\title{
Los retos del peritaje cultural. El antropólogo como perito en la defensa de los derechos indígenas
}

\author{
CHRISTOPHER LOPERENA, ROSALVA AÍDA HERNÁNDEZ CASTILLO Y MARIANA MORA
}

The Challenges of the Cultural

Expert Witness Report.

The Anthropologist as an

Expert in the Defense of

Indigenous Rights

CHRISTOPHER LOPERENA

University of San Francisco, San Francisco,

California, Estados Unidos

chrisloperena@yahoo.com

Rosalva Aída Hernández Castillo

Centro de Investigaciones y Estudios

Superiores en Antropología Social-

Ciudad de México, México

aidaher2005@gmail.com

MARIANA MORA

Centro de Investigaciones y Estudios Superiores en Antropología Social-

Ciudad de México, México

mariana_mora@yahoo.com

Desacatos 57,

mayo-agosto 2018, pp. 8-19 ara conformar el dosier de este número de Desacatos, invitamos a antropólogos a reflexionar sobre los retos metodológicos, epistemológicos y políticos que implica su labor como peritos en litigios que involucran a integrantes de pueblos indígenas. Si bien en México tenemos un largo camino recorrido en la elaboración de peritajes antropológicos, existen pocos textos en los que se haya reflexionado de manera crítica sobre las rutas metodológicas y los dilemas éticos, políticos y epistemológicos que hemos enfrentado al constituirnos como la "voz legitimada" que habla por la cultura de los pueblos con quienes trabajamos (CEAS, 2012).

Con esta preocupación en mente, en mayo de 2016, organizamos un taller en el Centro de Investigaciones y Estudios Superiores en Antropología Social (CIESAS), en la Ciudad de México, en el que nos reunimos los coordinadores y autores de los artículos que se presentan en este volumen, más Rita Laura Segato, María Teresa Sierra Camacho y estudiantes del posgrado interesados en estos temas. Los antropólogos que convocamos participaron en la elaboración de peritajes para casos paradigmáticos de pueblos indígenas y afrodescendientes en México, Guatemala, Honduras, Surinam y Guyana, presentados ante el Sistema Interamericano de Derechos Humanos, varias instancias de justicia en México y Guatemala, y el Tribunal Federal Electoral de México. Estos casos han sentado precedentes legales importantes para avanzar en la justiciabilidad de los derechos indígenas y afrodescendientes. De esta manera, nos dimos a la tarea de crear un espacio para reflexionar sobre el papel de la antropología en el activismo legal, así como sobre las posibilidades y límites del uso del concepto de cultura, y para analizar las implicaciones éticas y políticas de nuestra participación en la elaboración de peritajes.

Durante dos días, los participantes describieron con detalle su papel en los casos y expusieron sus inquietudes, incomodidades y 
dudas con el propósito de identificar puntos analíticos en común y fomentar un diálogo transnacional. A cada participante se le solicitó que tratara problemas metodológicos, dificultades de traducir el análisis antropológico al lenguaje legal, dilemas éticos y políticos de representar la "cultura" y la "tradición" ante el sistema de justicia, entre otras cuestiones. A pesar de trabajar en distintos contextos nacionales y tradiciones legales, identificamos preocupaciones en común concernientes a los retos epistemológicos y políticos del peritaje antropológico. Todos compartíamos un compromiso con la producción de peritajes que fortalecieran las demandas políticas y legales de nuestros interlocutores, que confrontaran de manera directa las lógicas racistas, sexistas y esencialistas del sistema judicial, las cuales conceden derechos sobre la base de la diferencia cultural, y que desafiaran la hegemonía institucional de los sistemas legales nacionales sobre los sistemas de justicia indígena (Cumes, en este volumen; Hernández, inédito; Sierra y López, inédito). No obstante, con frecuencia nos encontramos cómplices de interpretaciones esencialistas de la cultura indígena (Kirsch, en este volumen; Saavedra, en este volumen), en una postura que va en sentido contrario a nuestros trabajos académicos y aportaciones teóricas. A pesar de nuestros esfuerzos por escribir contra las jerarquías de conocimiento, muchas veces reproducimos la dominación epistemológica de la evidencia positivista por encima de las historias diversas, modos de conocimiento $\mathrm{y}$ afirmaciones ontológicas de la gente con quien pretendemos comprometernos (Loperena, inédito). La riqueza extraordinaria del diálogo sirvió como fundamento inicial para los argumentos que algunos de los participantes en el taller presentamos para integrar secciones temáticas sobre peritajes en dos revistas académicas. Los textos en español se incluyen en este número de Desacatos y se encuentran en diálogo con los de Christopher Loperena, María Teresa Sierra Camacho, Liliana López,
Charles Hale, Rosalva Aída Hernández Castillo y Mariana Mora, aún sin publicarse.

\section{Las reformas multiculturales y el antropólogo como experto}

En las últimas tres décadas, una serie de reformas constitucionales ha reconocido el carácter multicultural de los países latinoamericanos. Esto ha llevado al reconocimiento de jure del pluralismo jurídico y los derechos colectivos de los pueblos indígenas. En este contexto, los órganos judiciales han acudido cada vez más a los antropólogos y a las perspectivas que emergen de un continuo compromiso etnográfico con el objetivo de determinar la validez de las demandas culturales que fundamentan los reclamos por derechos colectivos. Los tres artículos de la sección "Saberes y razones" y los textos en "Testimonios" - el amicus curiae de Aura Estela Cumes Simón y el testimonio de Nestora Salgado García- y "Legados" toman como punto de partida la visión de que el peritaje antropológico es una forma de participación política, que demanda una negociación cuidadosa entre las jerarquías étnico-raciales, de género y de conocimiento entre los pueblos indígenas, los abogados, los jueces, los expertos y los defensores de derechos humanos. Por medio de un análisis detallado de casos emblemáticos en México, Guatemala, Guyana y Surinam, los artículos proveen una ventana a través de la cual se pueden examinar de cerca los efectos contradictorios de la producción de conocimiento por expertos, las oportunidades creativas y las limitaciones del concepto de cultura, así como las implicaciones sociojurídicas de la participación antropológica en casos emblemáticos.

En un contexto latinoamericano definido cada vez más por la judicialización de la política (Sieder, Schjolden y Angell, 2005), los juzgados y las cortes internacionales se han transformado en un 
importante terreno de disputa entre comunidades indígenas, afrodescendientes y los Estados. Su papel como peritos dentro de espacios que van desde los juzgados indígenas y estatales, hasta la Corte Interamericana de Derechos Humanos, ha proporcionado a los autores de este número de Desacatos una perspectiva privilegiada sobre la esfera de la justicia como campo en disputa. Su experiencia de observación participante como expertos les ha dado la posibilidad de analizar las prácticas cotidianas de construcción de la justicia en los sistemas nacionales e internacionales. Asimismo, han podido documentar cómo ciertos conocimientos sobre las culturas indígenas se legitiman y otros no, junto con los efectos racializantes y de género que tienen las construcciones discursivas que emanan del ámbito legal.

En el ámbito nacional, las reformas multiculturales implementadas en Latinoamérica en las últimas tres décadas han resultado en nuevos códigos de procedimientos penales que han reconocido el valor de los informes periciales antropológicos en casos que involucran a integrantes de pueblos indígenas y afrodescendientes. Estos peritajes culturales, también llamados affidavits antropológicos, y los testimonios expertos, conocidos como amicus curiae, ${ }^{1}$ son preparados por especialistas que describen el contexto cultural del acusado o de la víctima. El objetivo fundamental de los peritajes antropológicos consiste en proveer información al aparato de justicia sobre la relevancia de las diferencias culturales para la interpretación de un caso específico.

Para muchos antropólogos, el papel cada vez más importante de los peritajes culturales y los testimonios expertos sirve para fortalecer el acceso a la justicia de los pueblos indígenas y promover los procesos legales interculturales (CEAS, 2012; Sánchez, 2010). Otros autores sostienen una perspectiva menos optimista y advierten que, a pesar de que el uso de peritajes antropológicos representa un logro para el acceso a la justicia en comparación con las perspectivas racistas del pasado, que apelaban a un "atraso cultural", estos instrumentos plantean nuevos dilemas éticos y epistemológicos para los antropólogos involucrados en el activismo legal. Argumentan que esta herramienta reproduce las jerarquías epistemológicas que sitúan a los antropólogos como expertos poseedores del "conocimiento cultural legítimo”, reconocido por los funcionarios de la justicia (Escalante, 2012). Al mismo tiempo, el papel del antropólogo como "traductor cultural" está arraigado en las fuerzas reguladoras de los regímenes jurídicos, los cuales con frecuencia limitan las perspectivas contextuales del análisis antropológico (Carrasco, 2015).

Los cuatro autores de la sección temática "Saberes y razones" contribuyen a esta perspectiva crítica al estudiar desde perspectivas distintas los límites y posibilidades de conceptos antropológicos clave, en particular el de "cultura". En vez de limitar los peritajes culturales a la demostración de la permanencia de prácticas tradicionales, expanden su campo de investigación para situar las prácticas culturales en las estructuras de poder más amplias y remarcar las formas institucionales del racismo y el patriarcado implícitas en la maquinaria jurídica y el sistema legal. A su vez, cuestionan los efectos políticos de los límites ontológicos que comparten tanto la disciplina del derecho como la antropología (Loperena, inédito). Estas decisiones forman parte de los compromisos éticos y políticos de descolonizar la disciplina de la antropología y los regímenes

1 Expresión latina que significa "amigo de la Corte". Se utiliza para referirse a informes periciales o testimonios expertos presentados por terceros ajenos al litigio, que aportan criterios técnicos no vinculantes - en el caso del antropólogo, de carácter sociocultural- que posibilitan al tribunal contextualizar el hecho que se juzga. A diferencia del peritaje antropológico, el amicus curiae, por lo general, no debe sustentarse de manera oral y puede fundamentarse en documentos secundarios y en la experiencia del experto. Véase Defensoría del Pueblo (2009). 
de derecho. Sin embargo, estos compromisos activistas van contra la rigidez de las prácticas coloniales dentro del aparato judicial, las cuales reproducen visiones esencialistas y tendencias "civilizatorias" (Mora, inédito). Cada autor analiza de manera crítica cómo navegó en los terrenos disputados y las decisiones metodológicas y estrategias textuales que empleó en los peritajes culturales. El texto de Cumes Simón, en la sección "Testimonios", trata del amicus curiae presentado ante la Corte de Constitucionalidad de Guatemala. Ofrece un análisis introductorio del contexto de pluralismo jurídico marcado por el racismo y el legado colonial en el que se litigó el caso.

Tres colaboraciones se aproximan al tema de los efectos de género y raza de los casos legales. Sus autores discuten la manera en que un análisis de género culturalmente situado puede ayudar a desesencializar las concepciones de cultura y tradición, que muchas veces justifican la violencia hacia las mujeres indígenas (Saavedra, en este volumen). También se habla de cómo las poblaciones afectadas aportaron a la elaboración de peritajes y amicus curiae (Cumes, en este volumen), así como el papel de los testimonios en el veredicto final (Hernández y Salgado, en este volumen). Uno de los autores opta por recapitular su larga trayectoria de elaboración de peritajes antropológicos en México para reflexionar sobre las fronteras disciplinarias entre la antropología y la criminología, y las posibilidades y límites de esta colaboración (Ortiz, en este volumen).

Como ilustran los artículos en este número de Desacatos, a pesar de que son varias las contradicciones de la antropología jurídica comprometida políticamente, los antropólogos continúan haciendo este trabajo porque ser perito es un modo de participación académico-activista en un terreno altamente contencioso (Hale, 2006; Hernández, 2016). Muchos antropólogos han utilizado con éxito métodos colaborativos y participativos para, al mismo tiempo, abogar a favor de los derechos indígenas y contrarrestar las lógicas legales esencialistas (Hernández, inédito; Kirsch, 2001; en este volumen; Saavedra, en este volumen). En esta misma línea, el peritaje crea una oportunidad para usar nuestra formación antropológica y los conceptos clave de la disciplina para contribuir a la lucha por el acceso a la justicia de los pueblos indígenas y afrodescendientes con un alcance más amplio. Esta forma de participación activista sin duda genera contradicciones políticas importantes y preguntas epistemológicas complejas, que los autores de este volumen retoman de manera central.

El peritaje antropológico se utiliza por lo general para demostrar que la cultura indígena no sólo está presente en un lugar particular, sino que también es amenazada por fuerzas externas y que, por lo tanto, es merecedora de protecciones legales adicionales. El argumento de la "pérdida de cultura" entra en contradicción con la teorización contemporánea sobre la cultura como dinámica, procesual e históricamente contingente (Kirsch, en este volumen; Saavedra, en este volumen), así como con los estudios sobre la inconmensurabilidad de las ontologías que participan en terrenos político-jurídicos (De la Cadena, 2010; Blaser, 2013; Escobar, 2015; Mora, inédito). Aquí nos planteamos preguntas epistemológicas y preocupaciones éticas que retoman estas contradicciones. ¿Cómo reconciliamos, como peritos, estos métodos de percibir y saber sobre el "otro" (Clifford, 1988), en apariencia incongruentes? Los regímenes de derecho tienden a operar por medio de arquetipos ideales; sin embargo, es progresivamente más difícil para los pueblos indígenas y afrodescendientes adherirse a las definiciones establecidas que se requieren para acceder a derechos. ¿Cómo negociamos las expresiones históricamente contingentes de la formación de identidad con el uso efectivo, y con frecuencia pragmático, de los regímenes de derecho y el activismo legal antropológico? ¿Qué estrategias textuales y metodológicas debemos implementar para avanzar entre estas tensiones? ¿Qué 
implicaciones tiene el activismo legal para los antropólogos comprometidos con la descolonización de la producción del conocimiento?

En este volumen se tratan las posibilidades políticas y las limitaciones epistemológicas del activismo legal mediante el uso específico de peritajes culturales y amicus curiae. Los autores analizan las relaciones de poder y las jerarquías que forman parte del conocimiento y que confluyen en el proceso de elaboración de un informe pericial. Estas jerarquías sitúan el conocimiento y su validez dentro de ámbitos discursivos más abarcadores, los cuales delimitan, al menos de manera parcial, lo que puede decirse o no de los pueblos indígenas en el campo de la justicia. Mientras crean nuevas vías para que los pueblos indígenas accedan a la justicia, los procesos legales contribuyen a la reificación de la alteridad y con frecuencia refuerzan presuposiciones culturalistas sobre la autenticidad de las tradiciones y las prácticas de costumbre. Algunos de estos dilemas son estudiados por los autores de este número, quienes reconocen que las organizaciones indígenas y afrodescendientes recurren cada vez más a la judicialización de sus luchas políticas y buscan poner en entredicho las lógicas coloniales arraigadas profundamente en los espacios jurídicos promovidos por el Estado. Laura Edith Saavedra Hernández plantea la importancia del peritaje antropológico con perspectiva de género para desestabilizar los significados en torno a la cultura que tienen tanto los impartidores de la justicia del Estado como los grupos de poder dentro de las comunidades. Historizar las exclusiones de género en relación con la propiedad le permite mostrar cómo las prácticas de resistencia de las mujeres que demandan derecho a la tierra son también parte de la cultura que se busca reconocer.

La transcripción y la traducción cultural son herramientas fundamentales en la elaboración de peritajes antropológicos. En una primera etapa, el antropólogo transcribe observaciones de campo a etnografía. En una segunda etapa, traduce conceptos antropológicos a un lenguaje legible para el operador del aparato de justicia y transforma, en esencia, la cultura en "evidencia objetiva" (Good, 2008). Las experiencias vividas de dominación y violencia racial y patriarcal traducidas a jerga legal tienen el potencial de marginar aún más a los pueblos indígenas y afrodescendientes, al ofuscar cuestiones de racismo estructural e individualizar los daños colectivos (Jeffery, 2006).

Al mismo tiempo, esas contradicciones en apariencia irresolubles invitan a los antropólogos que participan en estrategias de activismo legal a elaborar herramientas metodológicas innovadoras y desarrollar maniobras textuales para extender de manera potencial las construcciones dominantes de lo que se entiende por ser "indígena", dentro de lo que se considera "conocimiento experto legítimo". En este sentido, los autores reunidos en esta entrega de Desacatos estudian la oportunidad de participar en el uso crítico de derechos desde abajo en modos que desestabilicen los ámbitos coloniales del poder como conocimiento (Hernández, 2016; De Sousa y Rodríguez-Garavito, 2005).

Estas reflexiones muestran de una manera u otra cómo el activismo legal antropológico intenta contribuir a la producción de nuevos discursos jurídicos en ámbitos altamente regulados. ¿Qué es traducible? ¿Qué no es traducible en el lenguaje de los derechos? ¿Qué es lo que ilustran las tensiones resultantes sobre cómo opera la ley, sobre las relaciones de poder en juego y la reificación de alteridades?

\section{Diálogos Norte-Sur y el activismo legal}

Tanto para el taller de peritajes como para la organización de esta publicación, fue fundamental establecer un marco analítico conjunto, que vinculara la antropología jurídica crítica estadounidense al pensamiento crítico latinoamericano. Estos diálogos 


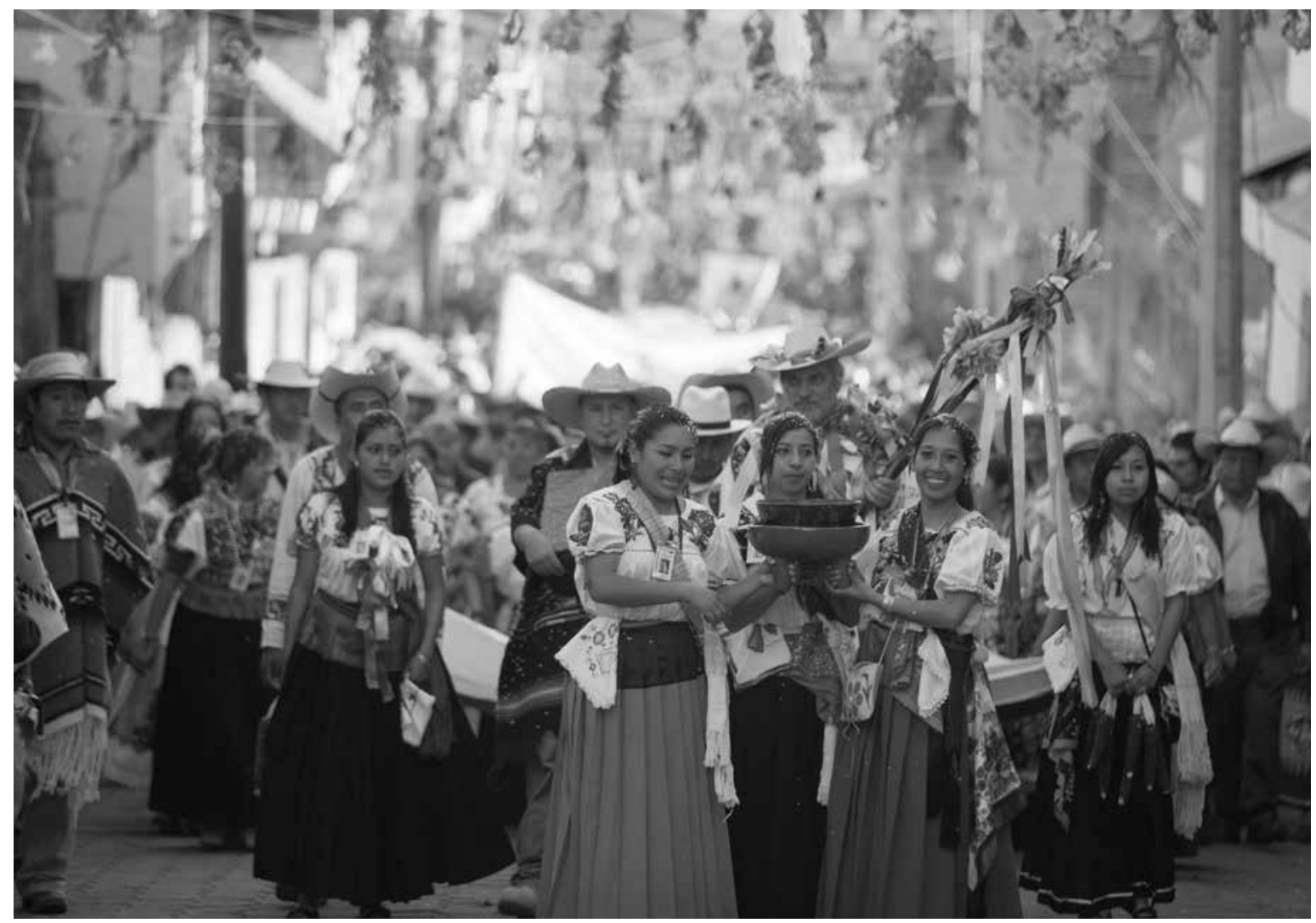

Prometeo Lucero Festejos del Fuego Nuevo en Cherán, Michoacán, febrero de 2013.

Norte-Sur no sólo son esenciales para enriquecer debates disciplinarios más amplios, sino que son relevantes políticamente, por el incremento de casos legales que involucran a inmigrantes latinoamericanos en busca de asilo o reconocimiento de su estatus como refugiados en Estados Unidos. En estos casos, los antropólogos, en su papel de "testigos expertos", proveen información contextual matizada que traduce las fuerzas político-económicas complejas y los elementos socioculturales con el propósito de relacionar las historias particulares de los países latinoamericanos con aquellas de Estados Unidos (Stephen, 2017).

En términos del pensamiento crítico latinoamericano, dos trayectorias disciplinarias particulares moldean el papel de los antropólogos como peritos en este continente. En primer lugar, la antropología social en nuestros países. Más que una disciplina humanista que se centre con rigidez en la crítica cultural, ha tendido a formar parte activa de procesos de cambio social. En países como México, en la década de 1940, los antropólogos se involucraron en los esfuerzos de construcción de un Estado-nación por medio del indigenismo, para más tarde tomar distancia de los proyectos de ingeniería social dirigidos por el Estado y participar de manera activa en movimientos sociales. En la década de 1970, bajo la influencia de las metodologías de educación popular de Paulo Freire (1970) y la investigación de acción participativa de Orlando Fals Borda (1979), antropólogos socialmente comprometidos pusieron énfasis en la promoción de conocimiento con bases populares como fundamento para modelos 
alternativos de desarrollo. Durante los últimos 20 años, la tendencia hacia la judicialización de la política, en la que los movimientos sociales canalizan sus demandas cada vez más mediante reivindicaciones basadas en derechos, ha llevado a los antropólogos socialmente comprometidos a incursionar en el ámbito del activismo legal. Es importante destacar que los académicos con base en Estados Unidos, que han acompañado movimientos sociales en el continente, han sido influidos de manera similar por esta trayectoria disciplinaria como parte de los diálogos Sur-Norte, por lo tanto, su trabajo académico se sitúa en esta gama más amplia de contribuciones y legados.

En segundo lugar, en Latinoamérica, los antropólogos han hecho contribuciones teóricas importantes en el ámbito de la antropología jurídica, en específico en términos del estudio del pluralismo jurídico y los derechos indígenas (Chenaut y Sierra, 1995; Sierra, 2004). Las historias de las antropologías jurídicas latinoamericanas están estrechamente ligadas a las alianzas establecidas entre los antropólogos críticos y las organizaciones indígenas que lucharon por el reconocimiento de sus derechos culturales y políticos. A principios de la década de 1980, se crearon espacios de reflexión colectiva, en diálogo con un dinámico movimiento indígena continental que denunciaba la permanencia del colonialismo interno, rechazaba la naturaleza monocultural de los Estados-nación latinoamericanos y exigía el reconocimiento de sus derechos territoriales y políticos. Como reverberación de estas demandas, en distintos países de Latinoamérica, los antropólogos se dieron a la tarea de analizar los marcos legales nacionales y explorar a mayor profundidad los espacios locales de administración de justicia (Stavenhagen e Iturralde, 1990; Sánchez, 1992).

Las teorías de colonialismo interno (González, 1963; 2006; Stavenhagen, 1969), combinadas con un análisis del poder y la desigualdad social, influyeron en las perspectivas críticas de la antropología jurídica latinoamericana desde sus orígenes. Conceptos como interlegalidad y pluralismo jurídico han sido centrales en el cuestionamiento de las perspectivas funcionalistas del derecho indígena, que continúan concibiendo el espacio legal como un ámbito autónomo que puede ser analizado con independencia de otros procesos económicos y sociales. La influencia de la economía política en las antropologías latinoamericanas contribuyó a cuestionar estos paradigmas teóricos y a dar origen a una antropología jurídica crítica que vincula el análisis del poder con el análisis de la cultura. Por ejemplo, Sierra Camacho analizó los procesos de disputa entre los nahuas de Puebla y los situó en el contexto de las relaciones de dominación con el Estado-nación. Desde una perspectiva integral, esta antropología jurídica crítica analizó las relaciones entre sistemas normativos dominantes y dominados, articulados por medio de estrategias desarrolladas por los pueblos indígenas cuando recurren a uno u otro (Sierra, 1992; Chenaut y Sierra, 1995). Sin embargo, la reflexión crítica de esta antropología jurídica no se limitó a analizar los contextos de dominación del llamado pluralismo jurídico, sino que, con base en estas reflexiones, se propusieron alianzas políticas para confrontar estrategias de dominación en contextos de colonialismo interno. ${ }^{2}$

2 Por ejemplo, el capítulo de Magda Gómez, "La defensoría jurídica de presos indígenas”, en el libro clásico de Stavenhagen e Iturralde (1990), denunció el racismo institucional del sistema de justicia mexicano y sentó las bases para el programa para liberar prisioneros indígenas promovido por ella en el Instituto Nacional Indigenista. Esta perspectiva teórico-política también orientó el trabajo de Stavenhagen como relator especial de la Organización de las Naciones Unidas en la Situación de los Derechos Humanos y Libertades Fundamentales de los Pueblos Indígenas. De 2001 a 2008, documentó y denunció las violaciones a los derechos de los pueblos indígenas en el ámbito internacional y sostuvo un diálogo permanente con organizaciones indígenas en los cinco continentes. 
Por su parte, en Estados Unidos, los antropólogos tienen una larga trayectoria de activismo legal crítico en casos que involucran los derechos de los pueblos indígenas y la población migrante (Diskin et al., 1986; Kearney, 1994; Fox, 2006). El supuesto dominio de la antropología en el estudio de las culturas y la larga historia de diálogos epistemológicos entre la antropología y el derecho (Ortiz, en este volumen) generaron las condiciones de posibilidad para que los antropólogos se volvieran elegibles como expertos ante las instituciones de justicia. Al mismo tiempo, los antropólogos empezaron a ser requeridos por las instituciones de justicia nacionales e internacionales, como expertos para opinar sobre la legitimidad de las demandas indígenas, en particular con referencia a la existencia de atributos culturales indígenas y la ocupación tradicional de un territorio definido. El peritaje antropológico de este carácter puede trazarse hasta 1946, después de que la Indian Claims Commission fuera autorizada a atender las demandas tribales contra el gobierno de Estados Unidos (Rosen, 1977: 567). En fechas más recientes, los antropólogos han sido llamados para ser peritos en casos de demandas de asilo y solicitudes de refugio (Stephen, 2017). A pesar de esta larga historia de vínculos entre la antropología y el derecho, reconstruida en el texto de Héctor Ortiz Elizondo, nuestro trabajo en la arena legal continúa produciendo intensos debates dentro de la disciplina misma. Estos debates giran en torno a la supuesta incapacidad de la ley para comprender los matices etnográficos (Clifford, 1988). Esta tensión y el potencial del análisis antropológico de la cultura para apoyar o socavar las demandas por derechos de los pueblos indígenas ha estimulado la producción de una naciente literatura académica sobre el peritaje y las prácticas textuales empleadas por antropólogos que deciden servir como peritos (CEAS, 2012; Guevara, Verona y Vergara, 2015; Geldres, 2016; Hernández, 2016).

Hemos invitado a cinco de los participantes de nuestro taller sobre peritajes antropológicos a compartir sus reflexiones. Desde trayectorias profesionales y espacios geopolíticos diversos, tenemos, por un lado, a dos de los pioneros en el peritaje antropológico en México, Ortiz Elizondo, como autor, y Yuri Escalante Betancourt, como comentarista. Se les unen las perspectivas de Cumes Simón, en Guatemala, y Laura Edith Saavedra Hernández, en Chiapas, México, quienes complejizan el análisis de los legados coloniales en el ámbito de la justicia a partir de los feminismos descoloniales. Estas experiencias dialogan con las reflexiones de Stuart Kirsch, quien nos lleva al contexto internacional para analizar las tensiones epistemológicas y metodológicas que enfrentó como testigo experto ante la Corte Interamericana de Derechos Humanos, en dos casos de defensa de derechos colectivos y territorios indígenas en Guyana y Surinam. Si bien cada autor reflexiona a profundidad sobre su propio papel como perito y analista de las culturas indígenas, no todos coinciden en el valor emancipatorio o regulatorio que le dan al peritaje como herramienta en el activismo legal. Creemos que la riqueza de sus contribuciones reside precisamente en esta heterogeneidad teórica y geopolítica.

\section{Las contribuciones de los autores}

Este número comienza con las reflexiones de Ortiz Elizondo, con casi 25 años de experiencia como perito independiente, quien dedica su colaboración a analizar lo que denomina la "mirada criminológica", como complemento de la "mirada antropológica”, para estudiar los aportes que el antropólogo como perito puede hacer a la justicia penal. Ortiz Elizondo hace una reconstrucción crítica de las contribuciones de la antropología al estudio de los hechos delictivos y muestra los múltiples entrecruces de fronteras disciplinarias que ha tenido la antropología con la criminología crítica. Para él, un elemento que las vincula es el interés por conocer 
los motivos detrás del comportamiento de los actores. En su trabajo, a partir de un caso en el que participó como perito ante la justicia penal, expone cómo el análisis cultural le permitió mostrar la falsedad de las acusaciones y cómo la intervención del antropólogo tiene lugar bajo el supuesto de que la mecánica de hechos es incontrovertible y que sólo se requiere incluir los factores culturales que condicionan su participación.

Un tema novedoso en esta contribución es la relevancia que toma el peritaje antropológico en México con el cambio del modelo inquisitorial al adversarial. Ortiz Elizondo señala que el modelo inquisitorial daba por hecho que la verdad histórica se alcanzaba con la obtención de datos duros y que el resultado de éstos era una definición objetiva de los hechos, por lo que solía prescindirse de la explicación de los motivos del inculpado. En el nuevo modelo adversarial, la subjetividad juega un papel mayor en la definición del delito porque las formas de valorar los actos que lo tipifican van cambiando. En este nuevo contexto legal, el autor argumenta que la antropología tendrá mucho que aportar a la comprensión de los motivos y su cuestionamiento más allá de una duda razonable, lo cual redundará en mayor acceso a la justicia para los pueblos indígenas en el modelo garantista que se pretende establecer en México.

También en el contexto mexicano, Saavedra Hernández reflexiona sobre su experiencia en la elaboración de un peritaje de género, realizado desde una perspectiva interseccional, en la defensa de una mujer tseltal acusada de despojo por su suegro por hacer efectivo su derecho a la tierra, después de una serie de experiencias de violencia doméstica que la llevaron a separarse de su esposo. Como parte de una investigación colaborativa, Saavedra Hernández se integra al trabajo de defensoría del Centro de Derechos de la Mujer de Chiapas, A. C., en el marco de una metodología de trabajo llamada defensa participativa, en la que las mujeres víctimas de violencia participan de manera directa en sus procesos legales, no sólo como parte acusadora sino como litigantes. Esta experiencia innovadora de lucha por la justicia, en la que se reconoce el pluralismo jurídico y se litigan los casos tanto en la justicia del Estado como en juzgados indígenas o ante las autoridades autónomas zapatistas, le da la oportunidad de realizar un peritaje que cuestiona las perspectivas esencialistas de la cultura y pone en el centro del informe pericial las concepciones que las mujeres indígenas tienen de sus derechos y su relación con la tierra.

En la arena internacional, Kirsch analiza los dilemas que enfrentó en la realización de dos informes periciales presentados a la Comisión y la Corte Interamericana de Derechos Humanos respecto a la defensa de los derechos indígenas a la tierra en Surinam y Guyana. En el primer caso, el peritaje se centra en mostrar los perjuicios ocasionados por la falta de reconocimiento legal por parte del gobierno de Surinam a los derechos a la tierra de los pueblos indígenas. En el segundo, se trata de un litigio por el territorio en una región indígena afectada por la minería artesanal y la minería a gran escala. En el análisis de ambos casos, las metodologías seguidas en la elaboración del informe pericial y los resultados de los litigios le permiten al autor comparar las posibilidades y limitaciones de la investigación etnográfica a corto plazo, así como reflexionar sobre los dilemas que implica hacer informes periciales en los que se dialoga al mismo tiempo con el aparato de justicia, los actores sociales y la comunidad académica.

En la sección "Testimonios" hemos incluido el amicus curiae realizado por Cumes Simón ante la Corte de Constitucionalidad de Guatemala. En este testimonio experto, se muestran las complejidades del entrecruce entre el racismo estructural que caracteriza la criminalización de la justicia indígena y la violencia patriarcal que sigue marcando la vida de las mujeres mayas. El amicus curiae se presentó en relación con un caso de violación sexual de una niña 
indígena, juzgado y sancionado por las autoridades comunitarias, pero cuya legitimidad no fue reconocida por un juez de primera instancia que alegó la ilegalidad de las "costumbres indígenas". En el documento legal, Cumes Simón analiza el contexto de pluralismo jurídico marcado por la desigualdad en el que se presenta el caso y reflexiona sobre el legado colonial que sigue caracterizando las relaciones entre el derecho del Estado y la justicia indígena en ese país centroamericano. Señala que se trataba de un caso muy complejo, por la gravedad de la violación sexual y los retos que implicaba reflexionar sobre el funcionamiento de la justicia indígena en un entorno de racismo colonial. Desde una perspectiva feminista descolonial, el informe pericial confronta tanto las perspectivas liberales de la persona que esgrimían los representantes de la justicia del Estado, como las visiones conciliatorias de la justicia indígena que corrían el riesgo de olvidar los deseos de la víctima. Por un lado, los fiscales defendían a la niña en tanto mujer, persona individual y víctima, como si se tratara de una huérfana de su familia, de su comunidad y de su ser indígena, a la vez que negaban la existencia de las autoridades y el derecho indígena. En oposición, esto provocaba una defensa de las decisiones de la autoridad y del derecho indígena, con el riesgo de olvidar a la víctima. En el artículo se reconstruyen los principales argumentos del amicus curiae por medio de la reflexión crítica sobre el contexto colonial en el que se realizan los peritajes antropológicos y los límites de éstos cuando se perpetúan las relaciones de desigualdad y neocolonialidad entre el derecho del Estado y el derecho indígena.
Hemos incluido, también en la sección de “Testimonios”, parte de la historia de Nestora Salgado García, comandanta de la Policía Comunitaria de Olinalá, Guerrero, considerada presa política por Amnistía Internacional, al ser víctima de la criminalización de la justicia indígena. Su historia fue escrita a dúo por ella y Rosalva Aída Hernández Castillo, coordinadora de este número. El testimonio recupera las entrevistas a profundidad realizadas en el marco de la elaboración del peritaje antropológico solicitado por sus abogados defensores. Ese informe pericial tuvo como objetivo argumentar que los delitos que se le adjudicaban, como secuestro y privación ilegal de la libertad, fueron detenciones legales realizadas en el marco de un sistema de justicia comunitaria indígena reconocido por legislaciones estatales, nacionales e internacionales. Las casi 200 páginas de entrevistas que dieron sustento al informe pericial le permitieron a Salgado García escribir su testimonio y narrar los retos que ha implicado defender los derechos de los pueblos indígenas y de las mujeres en un contexto marcado por la criminalización de las organizaciones indígenas, la violencia y la impunidad.

Publicar este texto, escrito por Salgado García, ya en libertad, y por alguien que fungió como perito en su defensa legal, es una manera de reivindicar la coproducción de conocimiento como una estrategia fundamental para la descolonización de la antropología. Esperamos que este número de Desacatos contribuya a la reflexión crítica sobre nuestro papel como académicos y analistas del derecho y la justicia, en un mundo cada vez más perfilado por las violencias estructurales, la desigualdad y la injusticia. D

\section{Bibliografía}

Blaser, Mario, 2013, "Ontological Conflicts and the Stories of People in Spite of Europe: Towards a Conversation on Political Ontology", en Current Anthropology, núm. 54, vol. 5, pp. 547-568.

Cadena, Marisol de la, 2010, "Indigenous Cosmopolitics in the Andes: Conceptual Reflections Beyond 'Politics'”, en Cultural Anthropology, núm. 25, vol. 2, pp. 334-370. 
Carrasco, Morita, 2015, "Diálogos de una antropóloga con el derecho a partir de su experiencia como perito en dos juicios penales", en Armando Guevara Gil, Aaron Verona y Roxana Vergara (eds.), El peritaje antropológico. Entre la reflexión y la práctica, Departamento Académico de Derecho-Centro de Investigación, Capacitación y Asesoría Jurídica, Lima, pp. 57-69.

Chenaut, Victoria y María Teresa Sierra (coords.), 1995, Pueblos indígenas ante el derecho, Centro de Investigaciones y Estudios Superiores en Antropología Social/Centro de Estudios Mexicanos y Centroamericanos, México.

Clifford, James, 1988, The Predicament of Culture: Twentieth Century Ethnography, Literature, and Art, Harvard University Press, Cambridge. Colegio de Etnólogos y Antropólogos Sociales (CEAS), 2012, Boletín Colegio de Etnólogos y Antropólogos Sociales, año 2012: Peritaje antropológico en México: reflexiones teórico metodológicas y experiencias.

Defensoría del Pueblo, 2009, El amicus curiae: ¿qué es y para qué sirve?, Defensoría del Pueblo (Serie Documentos Defensoriales, 8), Lima. Disponible en línea: <http://www.corteidh.or.cr/tablas/26654.pdf>.

Diskin, Martin, Thomas Bossert, Salomón Nahmad y Stéfano Varese, 1986, Peace and Autonomy in the Atlantic Coast of Nicaragua. A Report of the LASA Task Force on Human Rights and Academic Freedom, Latin American Studies Association, Pittsburgh.

Escalante Betancourt, Yuri, 2012, "Ética y verdad. La antropología frente al positivismo jurídico", en Boletín Colegio de Etnólogos y Antropólogos Sociales, año 2012, pp. 33-42.

Escobar, Arturo, 2015, “Territorios de diferencia: la ontología política de los 'derechos al territorio”, en Cuadernos de Antropología Social, núm. 41, pp. 25-38.

Fals Borda, Orlando, 1979, El problema de cómo investigar la realidad para transformarla por la praxis, Tercer Mundo, Bogotá.

Fox, Jonathan, 2006, "Lessons from Action Research: Partnerships: LASA/Oxfam America 2004 Martin Diskin Memorial Lecture", en Development in Practice, vol. 16, núm. 1, pp. 27-38.

Freire, Paulo, 1970, Pedagogía del oprimido, Tierra Nueva, Montevideo.

Geldres González, Carolina, 2016, "Zonas grises del peritaje antropológico en materia de derecho ordinario e indígena en los países andinos", en In Jure Anáhuac Mayab, año 4, núm. 8, pp. 85-114.

Gómez, Magdalena, 1990, "La desfensoría jurídica de presos indígenas", en Rodolfo Stavenhagen y Diego Iturralde (comps.), Entre la ley y la costumbre, Instituto Indigenista Interamericano, México.

González Casanova, Pablo, 1963, "Sociedad plural, colonialismo interno y desarrollo", en América Latina, año 6, núm. 3, pp. 15-32.

—_, 2006, "Colonialismo interno (una redefinición)", en Atilio A. Boron, Javier Amadeo, Sabrina González (comps.), Teoría marxista hoy, Consejo Latinoamericano de Ciencias Sociales, Buenos Aires, pp. 409-434.

Good, Anthony, 2008, "Cultural Evidence in Courts of Law", en Journal of the Royal Anthropological Institute, vol. 14, supl. 1, pp. S47-S60.

Guevara Gil, Armando, Aaron Verona y Roxana Vergara (eds.), 2015, El peritaje antropológico. Entre la reflexión y la práctica, Departamento Académico de Derecho-Centro de Investigación, Capacitación y Asesoría Jurídica, Lima.

Hale, Charles R., 2006, "Activist Research vs. Cultural Critique: Indigenous Land Rights and the Contradictions of Politically Engaged Anthropology", en Cultural Anthropology, vol. 21, núm. 1, pp. 96-120.

Hernández Castillo, Rosalva Aída, 2016, Multiple Injustices. Indigenous Women, Law and Political Struggle in Latin America, University of Arizona Press, Tucson.

_ _ inédito, "The Paradoxes of Expert Witness Reports in the Defense of Indigenous Justice Systems: The Case of Nestora Salgado García".

Jeffery, Laura, 2006, "Historical Narrative and Legal Evidence: Judging Chagossian's High Court Testimonies", en Political and Legal Anthropology Review, vol. 29, núm. 2, pp. 228-253.

Kearney, Michael, 1994, "Desde el indigenismo a los derechos humanos: etnicidad y política más allá de la mixteca”, en Nueva Antropología, vol. XIV, núm. 46, pp. 49-67.

Kirsch, Stuart, 2001, "Lost Worlds: Environmental Disaster, 'Culture Loss', and the Law”, en Current Anthropology, vol. 42, núm. 2, pp. 167-198. Loperena, Christopher, inédito, "Adjudicating Indigeneity: Anthropological Testimony in the Inter-American Court of Human Rights".

Mora, Mariana, inédito, "The Struggle for Life and Territory in the Case of the Ejido Ch'ol Tila in Chiapas, Mexico: Reflections on the Ontological Possibilities and Limits of Expert Witness Reports".

Rosen, Lawrence, 1977, “The Anthropologist as Expert Witness”, en American Anthropologist, vol. 79, núm. 3, pp. 555-578.

Sánchez Botero, Esther, 1992, “Peritazgo antropológico, una forma de conocimiento”, en El Otro Derecho, núm. 12.

—_, 2010, El peritaje antropológico. Justicia en clave cultural, Deutsche Gesellschaft für Technische Zusammenarbeit/Cooperación Técnica Alemana/ProFis, Bogotá. 
Sieder, Rachel, Line Schjolden y Alan Angell, 2005, The Judicialization of Politics in Latin America, Palgrave Macmillan, Nueva York.

Sierra Camacho, María Teresa (ed.), 1992, Discurso, cultura y poder: el ejercicio de la autoridad en pueblos hñahñús del Valle del Mezquital, Centro de Investigaciones y Estudios Superiores en Antropología Social/Gobierno del Estado de Hidalgo, México.

— 2004, Haciendo justicia. Interlegalidad, derecho y género en regiones indígenas, Centro de Investigaciones y Estudios Superiores en Antropología Social/Miguel Ángel Porrúa, México.

Sierra Camacho, María Teresa y Liliana López, inédito, "Cultural Expertise? Anthropologist as Witness in Defense of Indigenous and Afrodescendant Rights".

Sousa Santos, Boaventura de y César A. Rodríguez-Garavito, 2005, Law and Globalization from Below: Toward a Cosmopolitan Legality, Cambridge University Press, Cambridge.

Stavenhagen, Rodolfo, 1969, Las clases sociales en las sociedades agrarias, Siglo XXI Editores, México.

Stavenhagen, Rodolfo y Diego Iturralde (comps.), 1990, Entre la ley y la costumbre, Instituto Indigenista Interamericano, México.

Stephen, Lynn, 2017, “Bearing Witness: Testimony in Latin American Anthropology and Related Fields", en The Journal of Latin American and Caribbean Anthropology, vol. 22, núm. 1, pp. 85-109. 